\title{
Language Usage in Pakistani Classrooms
}

\author{
Pakiza Saba \\ Lecturer in English, Government College for women, Bhagtanwala (Sargodha), Punjab, Pakistan
}

\begin{abstract}
The use of code mixing, code switching and language borrowing is frequent in Pakistani classrooms especially when it comes to English language learning. The present study focuses on the ways in which codeswitching/mixing or language borrowing is considered helpful in teaching/learning and investigates the issues related to language choice and use in bilingual classroom discourse. The findings reflect the role of L1 as a strategy and aid in the classrooms to enhance students' learnability and teachers' effectiveness in comprehension and understanding of the concepts.
\end{abstract}

Keywords: Code mixing/switching, Language borrowing, bilingual classroom discourse

\section{Introduction}

Pakistan is a multilingual country where more than 70 languages including Urdu (the national language of Pakistan), English, and regional languages are used. In this context, language use is a very sensitive issue and Urdu/English controversy has serious implications. Globalization has also its impact on Pakistan and English emerged as significant language. Though the history of English in the language behaviour of this society dates approximately 500 years back when the British landed on the then India along with their language and local people had to learn English, which was an official language, to get a better job in government sector and students had to have a very good command over English because most of the books were written in English.

After independence, English remained the official language of the country and English is taught as the main language and as a medium of instruction in Pakistani classrooms. But because of multilingual society the use of code mixing, code switching and language borrowing is frequent in Pakistani classrooms especially when it comes to English language learning. Traditional ways about second language learning were limited to medium of instruction, use of methodology and curriculum based practices. These days applied linguistics and ELT has revolutionized this field and bilingual classroom discourse is of vital importance. Language alteration which is also referred to as code-switching is defined as the bilinguals' ability to alternate between the languages in their linguistic repertoires (Zentella, 1981). In Pakistan, insufficient attention is paid to the dimensions of bilingual classroom discourse and, now, it is significant to develop more understanding in the context of Pakistani bilingual classroom discourse. Code switching, code mixing and language borrowing are three major aspects of a bilingual classroom.

\section{Code Switching}

The bilingual speakers accommodate and mould their speech with the help of the two languages they know by alternating words from both the languages. Mesthrie, Swann, Deumert \& Leap (2000: p.146) determine codeswitching as a "switch back and forwards between languages, even during the same utterance". The speaker makes choice from the languages $\mathrm{s} /$ he knows to acquire the best possible expression. Romaine (1995: p.121) cites Gumperz (1982:p.59) that code switching is "the juxtaposition of within the same speech exchange of passages of speech belonging to two different grammatical systems or sub-systems". Poplack (1980) asserts that there are three types of code switching: Inter-sentential, Intra sentential and Tag switching. As far as the purpose of code switching is concerned, it is "to establish, cross or destroy group boundaries; to create, evoke or change interpersonal relations with their rights and obligations" (Gal, 1988: .247).

\section{Code-mixing}

Code mixing is also termed as intra-sentential switching. In code mixed sentences, pieces of one language are embedded in the other language while a speaker is basically using the other language. These 'pieces' of the other language are often words, but they can also be phrases or larger units. Discussing the purpose of code mixing, Kachru (1978: p. 36) asserts that there are basically three motivations for code-mixing i.e. "role identification, register identification, and desire for elucidation and interpretation". Muysken (2000:p.1) uses the term code mixing to refer to "all cases where lexical items and grammatical features from two languages appear in one sentence". It involves the mixing of words from one language into another and is practiced at the sentence level. Liu (2006: p.4) points out that code-mixing is the embedding of different linguistic units for instance affixes (bound morphemes), words (unbound morphemes), phrases and clauses from a "co-operative activity" where the discourse participants have to reconcile what they hear with what they understand if they really want to infer what is intended to be communicated by the speaker. 


\section{Code mixing in Urdu}

Discussing the phenomenon of code mixing in Urdu, Rasul (2009: p.41) asserts, "it is not new as a linguistic process; it pre-dates partition. Through this process new languages emerged from the old ones." Rangila, Thirumalai, \& Mallikarjun (2001) cite Grierson's 1901 census report on the mother tongues spoken in India that referred to situations where the natives mixed the English items in their own language (Rasul, 2009: p.41). According to Rasul (2009: p.42), after the creation of Pakistan Urdu was given the status of national language, but "certain factors- the colonial background, controversial issue of official language controversy over medium of education, and, prestige factor attached to English, industrialization and globalization- have added to the importance of English with the rising of every dawn". Today in Pakistan, English is an important component of education; and it is taught at schools as a compulsory subject. "The rush of English through the communication/ media channels has added to the exposure to English. One of the consequences is frequent code switching and code mixing, which in turn has resulted in the desertion of certain lexical items of Urdu" (Rasul 2009:p. 42). Today code mixing is common and frequently used in almost all spheres of life.

Ranging from informal conversations in everyday life to media discourse, from text books to newspapers and magazines it is frequently employed.

\section{Borrowing: An Overview}

Borrowing can be defined as "when any part of the structure of a language is changed by importation of features, whether from some other part of the same language or from some other external source, the imported features are said to be borrowed" (Hall, 1967:319). Depending on the source of borrowing we can categorize it as:

1) Internal borrowing

2) External borrowing

Mesthrie, Swann, Deumert \& Leap (2000: p. 249) view borrowing as "a technical term for the incorporation of an item from one language into another". He further explains that these items could be sounds that are least frequent, grammatical elements and words that are most frequently borrowed. These items are, through a constant use, a part of the language and the native speakers are often unaware of the original roots of that specific word. The speakers of a language might not be aware of a word that is borrowed. He gives example of the word 'donga' and 'fund' that many English-speaking South Africans are surprised to know that these are not a part of the English language (Mesthrie, Swann, Deumert \& Leap, 2000: p.249). They (2000: p.251) further comment that speakers prefer to borrow some terminology (register) from a language and continue speaking in their own language rather than shift and switch to another language. Borrowing, they consider, is a way of enriching one's language.

Hudson (1980: p. 55) elaborates that the main purpose or motive of borrowing can be either the intention to be identified with the native speakers or the non-availability of the word in the same language. Mesthrie, Swann, Deumert \& Leap (2000: p.250) identify the practice of borrowing in the technical terms related to long-distance travel, domestic appliances, computers, television and other forms of communication whereas Romaine (1995) points out borrowing of culture-specific items, e.g. food, dress, cultural institutions and activities etc. Stockwell (2002: p.138) asserts that there are certain constraints on borrowing as all the languages are not equally adjustable to borrowing. He asserts that all languages cannot "incorporate borrowed elements equally easily". In grammar for example if two languages are typologically different, borrowing is difficult than between two languages that are closely related to each other. Kachru, establishes the relationship of borrowing with code mixing by asserting, "code-mixed language types can easily be considered as examples of extended borrowing not restricted to the lexical level of a language. Borrowing is the initial step toward code mixing" (1978: p.31). However, to him it is not the only criterion as in the case of several South Asian languages. In Pakistan, too, the heavy linguistic borrowing, combined with social, economic, political, and international factors has led to code mixing. In this context, Sridhar (1978) asserts that three features of the text, that is the multi-level range on which mixing takes place, the non- cultural bound nature of the items and the dual grammatical system working for their mixing, help in differentiating code mixing from 'heavy borrowing'. He further asserts that the mixed elements do not necessarily fill a 'lexical gap' in the absorbing language; they exist side by side with perfectly acceptable equivalents in the absorbing language, forming an additional lexical stratum. It is conceivable that there might be a subtle pragmatic difference in the minds of the users of the mixed language between the mixed elements and their absorbing language counterparts, but such differences- if they exist- are extremely hard to characterize (1978: p.111).

\section{Difference between Code-Switching, Code-mixing and Borrowing: Overlapping of the Terms}

Romaine (1995) asserts that certain terms in linguistics such as borrowing, code switching and code mixing overlap at certain points. Code mixing and borrowing are so closely related and the difference is so subtle that sometimes it becomes difficult to distinguish whether the user has code mixed or borrowed an item. This 
problem cannot be solved merely on the basis of "degree of assimilation" since "assimilation is a gradient and not categorical concept" (Myers-Scotton, 2000:p.133). To her, the general hypothesis that borrowings show more assimilation is also not workable in many cases. , the general division that the insertions of L2 that carry a social significance are code switching but those that do not, are borrowings, is also problematic "since a borrowing can appear as code switch when it is a part of style switching" (Myers-Scotton, 2000:134). Mesthrie, Swann, Deumert \& Leap (2000: p. 249) differentiate between borrowing and code-switching that code-switching involves expertise of both the languages and the use of the technical rules of the languages too. Borrowing on the other hand, does not demand any of the two. Romaine (1995: p.124) seconds their view that "borrowing can occur in the speech of those with only monolingual competence, while code-switching implies some degree of competence in the two languages". According to Coulmas (2005: p.110), the difference between a borrowed and a switched word is one of frequency, clear only at the extremes of a continuum that relates both phenomena. Haugen (1956) as cited by Romaine (1995:p.143), also proposed that bilingual phenomena could be situated along a continuum of code-distinctiveness with switching representing maximal distinction, integration (or borrowing) representing maximal leveling of distinctions and interferences referring to over-lapping of two codes.

\section{Objectives of the study}

The following are the objectives of the research:

i. To focus on the ways in which code-switching/mixing or language borrowing is considered helpful in teaching/ learning.

ii. ii. To investigate the issues related to language choice and use in bilingual classroom discourse.

\section{Research questions of the study}

Q.1. How and why the use of code-switching and L1 is considered as an aid in the context of Pakistani classroom?

\section{Methodology}

Qualitative approach is used to get the data about the use of code switching, language borrowing and its impact on the classroom. Interview is selected as the tool to collect the data to get a deeper understanding of the issues of Pakistani classroom discourse.

\section{Data collection}

Data was collected from the students of university of Sargodha. 20 students were interviewed and asked various questions about the use of code switching and language borrowing in the classroom and the help they obtain when L1 is used in understanding and comprehending the lecture.

\section{Data Analysis}

All the interviews were read and the major points which emerged out of it were categorized which were used to produce themes and helped in data analysis and finally in drawing conclusion.

Code switching is a way to achieve academic targets. Teachers' goal is to transfer knowledge, impart skills and make the students understand and learn the lesson. He has to use different strategies and approaches while teaching in the classroom. English becomes hindrance when students are unable to comprehend the concept, terminologies and major ideas. So the teacher has to use shift to L1 and frequent code switching and mixing as they couldn't find similar words. At times the teachers have to use L1 in order to fill gap between speaking and listening and to avoid misunderstanding and wrong perception of the topic or concept. Teachers feel that lectures delivered in two languages, i.e., Urdu and English, are easier and result oriented instead of single language focused lectures.

Students learn better if they are taught through a medium other than English language especially if L1 is used. It becomes easier to understand the content and concepts and the students take interest in the lecture as the mere use of English makes lecture boring and varieties of languages develop interest of students. The inability to find appropriate lexical item is another reason to use L1 as students find a sense of comfort when lecture is delivered and discussed in two languages instead of English. Students hesitate to take part in discussions if only English is used because they haven't proper command on English language to speak in fluent way consequently, this thing makes them silent listener and passive learner.

\section{Conclusion}

English is undoubtedly the richest language of the world and widely used as second language and as medium of instruction in the global world as well as in Pakistan but it does not lessen the importance of other languages especially when it comes to language learning and teaching where the primary goal is the students' 
understanding of concepts so the use of another language let it be Urdu or other indigenous languages is an edge and a strategy for better comprehension of the topic. The use of L1 aids the teacher to make the student a better learner and focus on result oriented teaching and learning, aims to make the lecture interesting and to avoid wrong perceptions.

\section{References}

- Coulmas, F. (2005). Sociolinguistics: the study of speakers' choices. Cambridge: Cambridge University Press.

- Gal, S. (1988). The political economy of code choice. In M. Heller (Ed.) Code switching: Linguistic and anthropological perspectives (pp.247). The Hague: Mouton.

- Gumpertz, J.J. (1982). Discourse strategies Cambridge: Cambridge University Press

- Hall, R. A. Jr. (1967). Introductory linguistics. Philadelphia: Chilton Company.

- Haugen, Einar. 1953. Norwegian language in America. Philadelphia: University of Pennsylvania Press, Vol. 1. Haugen, Einar. 1953. Norwegian language in America. Philadelphia: University of Pennsylvania Press, Vol. 1.

- Hudson, R.A (first published: 1980, second edition: 1996) Sociolinguistics. Cambridge: Cambridge University Press.

- Kachru, B. B. (1978). Towards structuring code-mixing: An Indian perspective. B Kachru., and S.N Sridhar (Eds.) International journal of the sociology of language. Aspects of Sociolinguistics in South Asia. (16). New York: Mouton Publishers

- Liu, P. (2006). Code-switching and Code-mixing (seminar paper). Germany: GRIN. Retrieved January 15, 2012, from http://www.grin.com/en/ebook/ 92496/ code-switching-and-code-mixing

- Mesthrie, R., Swann, J., Deumert, A., \& Leap, W.L. (2000). Introducing sociolinguistics. Edinburgh: Edinburgh University Press.

- Muysken, P. (2000). Bilingual Speech: A typology of Code-Mixing. Cambridge: Cambridge University Press.

- Myers-Scotton, C. (2000) Code -switching as indexical of social negotiations in Li Wei (Ed.), The bilingualism reader (pp. 133-134). London: Routledge

- Muysken, P. (2000). Bilingual Speech: A typology of Code- $\quad$ mixing. Cambridge: Cambridge University Press.

- $\quad$ Myers -Scotton, C. (1993). Social motivations for code switching Oxford: Clarendon Press.

- Poplack, S. (1980) Sometimes I'll start a sentence in English termino en espauol: toward a typology of code switching (pp.221-256). In Li Wei (Ed.) The bilingualism reader. London: Routledge

- Rasul, S. (2009). Code- Mixing and Hybridization in Pakistan-Linguistic, Socio- Cultural and Attitudinal Perspectives. Germany: VDM

- $\quad$ Romaine, S. (1989). Bilingualism Oxford: Basil Blackwell.

- $\quad$ Romaine, S. (1995). Bilingualism (2nd ed.). Oxford: Blackwell Publishers Limited.

- Sridhar, S. N. (1978) On the functions of code -mixing in Kannada, B.B Kachru, \& S.N. Sridhar,(Eds.). International Journal of the Sociology of Language Aspects of Sociolinguistics in South Asia. (16), 109-117. New York: Mouton Publishers.

Author Profile: Pakiza Saba received the M.A and M.Phil degrees in Applied Linguistics from University of Sargodha in 2010 and Minhaj University, Lahore in 2014.She served as Lecturer in English at University of Sargodha, women campus Faisalabad. Recently, she is working as Lecturer in English at Government College for women, Bhagtanwala (Sargodha). 